\title{
Interpretation keys in the process of sensitization and education of the Chinese consumer as to the consumption of wine
}

\author{
Alessandro Trotta ${ }^{1,2}$, Stefano Massaglia ${ }^{1}$, Silvana Ballotta ${ }^{2}$, Stefania Palma ${ }^{2}$, Isabelle Bailet ${ }^{2}$, and Chao Liu ${ }^{2}$ \\ ${ }^{1}$ Università di Torino, DISAFA, Largo Paolo Braccini, 2, 10095 Grugliasco (TO), Italy \\ ${ }^{2}$ BS Business Strategies, via De’ Bardi, 28, 50125 Firenze, Italy
}

\begin{abstract}
China' wine consumption has ever and ever increased during the last decade but there are still difficulties in the communication of this product. This is caused by the great social, cultural and economical diversities among Chinese themselves and between eastern and western culture. In fact, the diversities between the population of urban areas of greater development and the rural ones and the differences between the profound and radical eastern culture and the western culture outline a very different consumer-type compared to the western one. For this reason, for years, the marketing strategies in the wine sector have not brought about the attended results. The Chinese wine consumer reveals much instability caused by cultural reasons, which have emerged in this work, joined by an experimental analysis that could bring into light reliable evaluative results. The output of the analysis of these results is a list of interpretation key points that can be used as a tool to improve the education and the communication towards Chinese wine consumer.
\end{abstract}

\section{Introduction}

The education process as well as that of sensitization of the Chinese consumer-type becomes essential especially in a time, such as the current one, of high wine-consumption propensity. We needed to focus on the new kind of consumer, which in the market place could represents the major interest in terms of developing trading capacity of the Europe businesses. Focusing on different market analysis and studies we realized that more attention must be paid to the young consumers belonging to the upperlmiddle social class, mainly in big cities [1]. The changes of habits, customs and social attitude have created a new type of consumer influenced by the globalized capitalism and therefore extremely open to the western wine philosophy [2]. In this regard, another fundamental data is the passage of some cities from the second band to a new first band. Chengdu, Nanjing, Chongqing, Shenyang, in particular, are having a very radical economic and social transformation [3]. This band is assumed to be even more attractive than the first band; this is because the new consumer is more flexible, dynamic and responsive to the West [4]. In addition, the population of these cities is very young, and this aspect will raise into account the choices of the Chinese population policy. Young people possess the ideal profile as conscious consumers, sensitive to the concept of origin and territoriality [5]. Moreover these new bands are partly projected towards globalization and partly modeled on the lifestyle of the old class wealthy Chinese. Despite these new interesting trends the Chinese market has always been changeable and unforeseeable. We have found the reason in the lack of a model able to let the wine become a real evaluation key of an eno-gastronomy culture so charming but away from their uses and traditions. Without this model the item wine becomes a victim of the trend of the moment and is not able to integrate with the daily habits of the consumer [6]. The main reason of this trend is not the absence of functional strategies but a wrong selection of the goals, in most cases caused by the will to get more results as soon as possible. The major example is the explosion of the French wine in the first decade of " 00 [7]. The item "wine" adopted the denomination of "luxury product" as an expression of status symbol. The French Brands benefited of it especially for their functional and easy way of communication. Therefore we can say that they have been the pathfinders of this unknown part of market place. The consequence apparently laudable, over time is showing its worst part, on one hand for the brand and on the other one for the kind of product and for the buckling and the incoherence of the consumer. In most cases, in fact, the brands are more appealing than product itself. But it exists a big an increasing number of consumers that is closer to the occidental ones and is ready to accept a new model able to include the eno-gastronomy culture in its ordinary life. This type of consumers is becoming interesting and alluring but it is still not clear which could be the right way to communicate our messages to them. Therefore the sinicization's process in the communication of the product "wine" becomes fundamental to reach this goal. Translating the messages of the wine culture involving cultural, rural, agricultural, scientific, playful and social aspects it is not so easy. Especially Italy as a country has lots of different rural places so composite to map out. The ampelography diversity of the grape as the best expression of a place rural identity, that changes zone by zone, is really hard and complex to evaluate and to remember for the Chinese consumer. In fact, we notice that when the Chinese practitioners first approach to a new wine they simplify the messages, preserving only the essential elements. Considering this overall view about the 
Chinese consumer, the objective of our experimental analysis is to identify some key points that can be used in the process of language adaptation needed for the education of the Chinese consumer.

\section{Materials and methods}

The first problem concerning education is communicating the messages with the correct significance. In order to obtain the opinion of the consumer about this topic it has been selected a diversified group of wine operators such as importers, suppliers, restaurateurs, sommeliers, wine lovers, journalists, producers and wine critics. The experiment has been carried forward by dividing the research in three phases. The first phase was based on a questionnaire given to a sample of 50 operators during a wine-tasting where they tasted 5 wines of the same trading name but with great differences in packaging. The questions addressed to the operators were aimed at understanding which was the most preferred wine and label as well as the objective and subjective motives in terms of choise of the interviewed. The second phase of the experiment involved the Incoming in October 2014 to four different Italian regions (Veneto, Alto Adige, Marche and Umbria) of a group of journalists from the most-sold wine reviews in China, the Revue du Vin de France (RVF). Nine wine cellars had been visited; these cellars were different one from the other in the communicative philosophy of the brand. Thereafter a questionnaire was given out so as to identify the objective and subjective preferences of the professionals on the quality of the wine and the bottles' esthetics. The last part of the experiment led to presenting to the same operators of the first experiment, after a period of six months, the consortium's logo of each of five previously tasted wines without revealing the logo's meaning. The questionnaire outlines both the recognizability level of the Logo and some personal and subjective perceptions of the imparted signals of the logo.

\section{Data analysis}

\subsection{Carignano del Sulcis event questionnaire}

The outlines emerged from the questionnaire on the Carignano wine in Shanghai will point out the positive and negative elements of the tasted bottles during the event. Is Arenas and Terre Brune have turned out with a good level of attraction as a whole towards the Chinese Consumer. Labels of medium large dimension are in fact appreciated by Chinese consumers. This is because they are more attracted by the products of quick and greater recognizability. Despite the success of wine in production areas such as Borgogna and Barolo, which have bottles with Burgundy Style and Freisa shapes, the Bordeaux Style shape has been the most successful. The fact is that the first wines which colonized the market have been those of Bordeaux's and for years they have represented the high quality wine in China. Others important elements are the images and symbols which are included in the labels. As a matter of fact, recalling the olden days is always very functional from Marketing's point of view. The images in Is Arenas and Terre Brune labels represent ancient Italian findings which remind traditional elements of the Chinese culture. In case of the Buio Buio label, the label is small with an abstract image. It is important to notice that cellars like Mesa have been awarded many times for their bottles' graphics made in Italy; Buio Buio has turned out to be one of the most appreciated labels. From what has emerged from the questionnaire, it seems unattractive to the Chinese consumer. On the Tupei wine's label, there is an image, which represents a vessel, typical of the island from which the product came from and after which the cellar is named: Calasetta. The Chinese consumer is therefore confused by an image, which distances him/her from the wine symbols in his/her imaginary. The most relished bottle has turned out to be the Barrua. The label is characterized by several concentric cycles in which diverse symbols and signs are distinguished. Independently from the meaning that they have in the western or eastern world, the presence of all these components strongly recalls the mystical symbolism, extremely attractive to the Chinese people [7]. Symbolism can be counter-productive if it is considered from a religious point of view. It is good to keep in mind that the Chinese population has been proudly distinguished for its secular culture. With regards to colours, golden colour remains to be the most catchy, especially when it comes to details. Even the red colour, in line with what has been drawn from the bibliographic analysis, seems to have an outstanding appeal. Dark yellow and beige in the Barrua and Terre Brune remind of the antique chart. Everything that recalls antiquity is extremely attractive for the Chinese. The dark uni-colours such as black and blue in the Tupei and Buio bottles have indeed been unattractive.

\subsection{Recognition Carignano logo questionnaire}

In the questionnaire emerged that the logo of Carignano del Sulcis Consortium has found great success, in fact, a great deal of people recognized it by identifying it with its real meaning. It is essential to consider that the type of person interviewed will interface daily with the western reality and with the signals that it sends. The most important discover is the association that is made with the imaginary historical cultural society of China. To be effective the symbol or sign with which you want to try to attract must recall proximity and familiarity with the culture of belonging. It is requested a deep knowledge of Chinese culture to use the right signals and symbols in the communication towards the consumer, considering their importance in Chinese culture.

\subsection{RVF questionnaire's elements of interest}

The Chinese market is always more interested in Italian products, especially regarding the wine sector. The most important Chinese wine magazine has a French name since French products have identified wine for several years. The initiative, which has involved RVF and Italy by dedicating a specific publishing proposal for the Chinese market, shows how much Italy can portray a steady and important position within the wine realm in the future. By evaluating the emerging points from the RVF questionnaire, the following conclusions can be drawn: 
- A Chinese person with a medium-high competence on wine is able to analyze and comprehend the distinguishing elements of the product. The latter are the producers' aim so as to add value and thereby represent the true essence of the western wine quality conception.

- The Chinese consumer has a different approach to the sensory analysis. A major importance is given to the olfactory analysis; the scent and odor description covers most of the wine description. This is the reason why aromatic wine is expected to be a major success in the future.

- Food-wine combination is an extremely important factor. As it has emerged from our research, finding a meeting point between the two cultures by placing side by side the Chinese cuisine products and our wine is fundamental. This would grant double benefit; on one hand the wine product can be included in everyday habits and thus enhance the meals quality while on the other hand it would lead wine sinicization in the collective imagination. In this regard the importance of white wine needs to be remarked (from what has emerged so far, considering point 2 , aromatic white wine is the type which better adapts to the culinary Chinese style).

- The journalists' opinions about the wine tasted and those suggested to their readers do not always coincide. For better understanding, it is important to comprehend the concept of "drinkability" according to Chinese people. There, alcohol tolerance is less than ours (the success gained by beer with low alcohol content is an example), therefore the wine equilibrium needs to be searched among products with low alcohol content. Moreover, there is another problem - the so-called syndrome "Asian glow". The global market requires a common effort to produce a wine with less alcohol. This output will have to be associated with an extremely balanced wine in the case of Chinese market. For example, Prosecco is now going through a period of major success which is destined to grow. This product has a strong-point because it is a sparkling wine and, in the Chinese imaginary, can be linked to the idea that Champagne has given in these years.

An important data appears from the articles published on the visited companies by the RVF's delegation. The messages of attraction and appreciation which normally are launched to the western world can turn out to be of no value for the eastern world. Many wine cellars tend to emphasize on their story and their affinity to important aristocratic families. Terms such as Dutch and Marquis have no meaning in China. On the contrary, according to the communist culture, seeking to emerge as family above others has a negative meaning. instead of mentioning aristocratic names, it is better to highlight the strong family membership bond and the efforts, which have been done in the past to keep it united and strong (a fundamental symbol in the Chinese culture). All this brings back to the importance of the sinicization process not only in the launched messages but also in the contents if necessary.

\section{Conclusion}

Creating a language to communicate in an easy and adaptable way is fundamental to succeed in educating the Chinese consumer. From the results of the research it is possible to state that the consumer education has to be focused on the following key points:

- Simplification of the language, always reminding that communication has to take into account how the messages can be interpreted by the cultural point of view of the Chinese consumer.

- A homogeneous communicative format is necessary for an optimizing meeting between request and offer.

- Graphics has a higher importance in the eastern world compared to the western culture, therefore, considering the principles emerged from this research it becomes an essential aspect of the communication, particularly when it comes to colors, symbols and shapes.

- The Chinese social pattern needs to be respected so as not to offend the consumer.

- The formation process has to involve local actors (Chinese operators).

- The homogeneity effect needed to promote wine in China can be reached only going deep into the different aspects of the Chinese culture.

\section{References}

[1] Child P. Lesson From a Global Retailer: An Interview with the President of Carrefour China, Chi.Tod., (2006)

[2] P. Borzatta; M. Miranda, A. Spalletta. Consumi interni: quello che i cinesi vogliono, L'asi. Edi, 9, 98-114, (2013)

[3] F. Bosco, Vino Italiano in Cina, Studio sulla presenza del vino italiano in Cina, Ope., 22, (2009)

[4] T. S. Chan, Consumer Behaviour in Asia, International Business Press, (1999)

[5] Y. Chen, J. Penhirin, Marketing to China's Consumers, McKi., (2004)

[6] G. Criveller, G. Ricci, Missione e Ragione, Pimedit, Milano, (2010)

[7] M. Loewe, E. L. Shaughnessy, The Cambridge History of Ancient China, Cam. Uni, 123-178, (2011) 